\title{
Contrast-enhanced ultrasound (CEUS) of the abdominal vasculature
}

\author{
Vasileios Rafailidis $\odot$, Cheng Fang, Gibran T. Yusuf, Dean Y. Huang, Paul S. Sidhu \\ Department of Radiology, King's College London, King's College Hospital, Denmark Hill, SE59RS London, England, UK
}

\section{Abstract}

Vascular diseases account for a significant proportion of abdominal pathology and represent a common referral source for abdominal ultrasonographic examinations. B-mode, color Doppler, and spectral Doppler analyses are well-established in the evaluation of abdominal blood vessels although they may occasionally be limited by lower sensitivity for slow flow visualization or the deeper location of abdominal vascular structures. The introduction of microbubbles as ultrasonographic contrast agents has rendered contrast-enhanced ultrasound (CEUS), a valuable complementary ultrasonographic technique, which is capable of addressing clinically significant problems and guiding patient management. The purpose of this pictorial review is to analyze the use of CEUS in the evaluation of abdominal vascular pathology and illustrate such applications by presenting representative images. Pathology discussed includes abdominal aortic aneurysm, post-endovascular treatment aorta, portal vein thrombosis, abdominal vascular trauma, and organ transplantation along with its complications.

Key words: Contrast-enhanced ultrasoundAorta-Portal vein-Aneurysm-Endoleak-Trauma

Ultrasonography (US) is a well-established first-line modality for the evaluation of abdominal symptoms. Vascular diseases account for a significant part of abdominal abnormalities comprising a wide spectrum of conditions including arterial and venous diseases, diseases affecting native organs, post-operative surveillance and detection of complications, benign and malignant entities, and follow-up of transplantation. Its widespread

Electronic supplementary material The online version of this article (doi:10.1007/s00261-017-1329-7) contains supplementary material, which is available to authorized users.

Correspondence to: Vasileios Rafailidis; email: billraf@hotmail.com use is based on numerous advantages, including low cost, repeatability, potential to be performed at any location from the patient's bedside to the operating room, good patient tolerability, and the absence of contraindications. Nevertheless, US has inherent limitations and in some cases may not successfully address all clinical demands. Inappropriate body habitus, the presence of overlying gas-containing intestinal loops, deep position of abdominal organs, and vascular structures are important limitations for the ultrasonographic evaluation of abdominal abnormalities. When it comes to abdominal vascular diseases, color and power Doppler techniques along with spectral analysis are essential for diagnosis but again have inherent limitations like Doppler angle dependency, limited sensitivity to slow flow, and aliasing or blooming artifact [1]. These limitations are usually accommodated by the performing physician but may hinder proper diagnosis in challenging conditions like the detection of a small or delayed endoleak or the identification of neovascularization within a malignant portal venous thrombus. Computed tomography angiography (CTA) and magnetic resonance angiography (MRA) are currently the reference methods for diagnostic evaluation of abdominal vascular abnormalities, overcoming US limitations, and meeting clinical imaging needs. However, there are situations where CTA and MRA should be avoided, including patients with renal impairment, cardiac pacemakers, and metallic foreign bodies. In a number of patients, US will be the sole imaging modality.

Recent significant technological advances in US with the introduction of elastography and contrast-enhanced ultrasound (CEUS) have expanded capabilities, with the term multiparametric ultrasound (MPUS) used to encompass all the facets of US [2]. Contrast-enhanced ultrasound, using microbubble as ultrasonographic contrast agents (UCA), has gained wide acceptance in many clinical scenarios, culminating in the publication of numerous official recommendations [1]. The recent Food and Drug Administration (FDA) approval for an UCA 
Table 1. Summary of CEUS applications for various abdominal vascular systems

\begin{tabular}{|c|c|c|}
\hline $\begin{array}{l}\text { Vascular } \\
\text { system }\end{array}$ & Applications & Specific strengths over CTA \\
\hline Native aorta & $\begin{array}{l}\text { Delineation of mural thrombus blood flow within an aneurysm } \\
\text { Detection of active extravasation in ruptured AAA } \\
\text { Detection of aorto-caval fistulas } \\
\text { Detection of aortic dissection }\end{array}$ & $\begin{array}{l}\text { Detection of rupture signs in the emergency department } \\
\text { However, an MDCTA should always be performed when } \\
\text { available }\end{array}$ \\
\hline $\begin{array}{l}\text { Post-EVAR } \\
\text { aorta }\end{array}$ & $\begin{array}{l}\text { Detection and characterization (classification) of endoleaks } \\
\text { Quantification of aneurysm enhancement }\end{array}$ & $\begin{array}{l}\text { Dynamic evaluation } \\
\text { Prolonged scanning } \\
\text { Better characterization of endoleaks } \\
\text { Lack of nephrotoxic contrast agent and ionizing radiation, } \\
\text { suitable for long-term follow-up }\end{array}$ \\
\hline Portal vein & $\begin{array}{l}\text { Improved detection of portal vein thrombus } \\
\text { Characterization of portal vein thrombosis as benign or } \\
\text { malignant }\end{array}$ & $\begin{array}{l}\text { Increased spatial and temporal resolution within the field-of- } \\
\text { view } \\
\text { Improved detection of neovessels }\end{array}$ \\
\hline Renal arteries & $\begin{array}{l}\text { Improvement of renal arteries evaluation with Doppler } \\
\text { technique }\end{array}$ & - \\
\hline $\begin{array}{l}\text { Hepatic/me- } \\
\text { senteric } \\
\text { arteries }\end{array}$ & Improvement of mesenteric artery evaluation & - \\
\hline Trauma & $\begin{array}{l}\text { Detection of parenchymal injuries } \\
\text { Detection of vascular pathology like pseudoaneurysm or active } \\
\text { bleeding }\end{array}$ & $\begin{array}{l}\text { Real-time evaluation } \\
\text { Prolonged continuous scanning }\end{array}$ \\
\hline $\begin{array}{l}\text { Transplanta- } \\
\text { tion }\end{array}$ & $\begin{array}{l}\text { Detection of vascular complications like hepatic artery and } \\
\text { portal vein thrombosis or stenosis }\end{array}$ & $\begin{array}{l}\text { Real-time evaluation } \\
\text { Prolonged continuous scanning }\end{array}$ \\
\hline
\end{tabular}

for characterization of focal liver lesions in adult and pediatric patients is expected to further increase the use of CEUS in the United States [3]. With regard to abdominal vascular pathology, CEUS has been investigated in many applications although considered particularly valuable in the detection and characterization of aortic endoleaks, identification of aortic dissection and rupture, and for differential diagnosis of neoplastic vs. bland thrombus in the portal vein and inferior vena cava (IVC) $[1,4]$. Beyond the unenhanced ultrasonographic technique's inherent advantages previously described, CEUS is also characterized by improved flow visualization even in extremely small-caliber vessels, for example, in tumor neovessels, superior spatial and temporal resolution in real-time evaluation, and increased contrast between blood flow and avascular tissues. This relies on the unique property of UCA to strictly remain within the vascular tree, incapable of diffusion through the vessel wall as their size does not permit this. Moreover, CEUS advantages include dispensing of any prior laboratory tests, excellent safety profile, and limited contraindications $[1,3,5]$.

The purpose of this article is to provide an overview of CEUS applications in abdominal vascular abnormalities based on the current literature, and furthermore to present characteristic cases where CEUS proved valuable for diagnosis. The main focus will be in aortic abnormalities including abdominal aortic aneurysm and postoperative surveillance for early detection of endoleaks and venous pathology including neoplastic thrombosis. Less widely performed applications will also be detailed, as summarized in Table 1.

\section{Technique and safety}

CEUS is performed with the intravenous administration of a bolus dose of the UCA, and essentially always performed after a complete unenhanced ultrasonographic examination. This allows the examiner to identify the area of interest, establish an initial opinion, ascertain the viability of a subsequent CEUS examination and plan the procedure to maximize the diagnostic outcome. Once the unenhanced ultrasonographic protocol is complete, having appreciated the gray-scale, color, power Doppler, and spectral analysis findings, an intravenous catheter can be placed in the antecubital fossa. It is best to insert the intravenous catheter following the baseline US to avoid unnecessary cannulation if the CEUS examination is not deemed useful. In general, the amount of UCA administered varies depending on the ultrasound machine's sensitivity and the product used. SonoVue ${ }^{\mathrm{TM}}$ (Bracco SpA, Milan, Italy) is the most widely used contrast agent in Europe and consists of microbubbles containing an inert gas (sulfur hexafluoride) encapsulated by a phospholipid shell, marketed as Lumason $^{\text {TM }}$ (Bracco SpA, Milan, Italy) in the United States. A dose of $2.4 \mathrm{~mL}$ of Lumason ${ }^{\mathrm{TM}} /$ SonoVue $^{\mathrm{TM}}$ per injection is considered adequate for the liver and other abdominal vascular procedures. A second dose of $2.4 \mathrm{~mL}$ can be administered if needed. UCA are strict intravascular agents, large enough $(10 \mu \mathrm{m})$ to preclude passage through the vascular endothelium, but small enough to circulate through small capillaries. Crucially, the metabolism of UCA renders them independent of renal excretion, the phospholipid shell is metabolized by the liver and the contained inert gas is exhaled by the 
lungs. As a result, CEUS can be safely performed in patients with renal impairment. In order to achieve optimal visualization of the UCA, a contrast-specific ultrasonographic technique should be applied. Pulse inversion and amplitude-modulation techniques which in general suppress echogenic signals originating from static tissues while visualizing echogenic signals produced by oscillating microbubbles are used. This results in the optimal echogenicity distinction between UCA and static tissues and offers the best spatial and temporal resolution. Two valuable techniques in vascular CEUS include the replenishment mode after a high-Mechanical Index pulse and the Temporal Maximum Intensity Projection (MIP) mode. In the first technique, a high-MI ultrasound pulse is used to disrupt all the microbubbles lying within the imaging field with replenishment allowing observation of the enhancement pattern of structures. In the second technique, the ultrasound device aggregates bright echoes of the UCA and creates cumulative images which illustrate the vascular pattern or architecture of structures under investigation $[1,3,4,6]$.

Among its advantages, CEUS can be performed without any prior laboratory examination as impaired renal function is not a contraindication for administration of UCA, contrary to CTA and MRA. The contraindications for CEUS are limited and include known history of allergic reaction to the UCA itself, severe pulmonary hypertension and pregnancy. The contraindication of right-to-left shunt has been recently discontinued [1, 7]. SonoVue ${ }^{\mathrm{TM}}$ has been extensively investigated for adverse reactions and has an excellent safety profile. Serious adverse reactions occurred in only $0.0086 \%$ of patients and treatment was necessary in only four patients. This adverse reaction rate is considered comparable to the rate of MR contrast agents and lower than CT contrast agents $[1,8,9]$. CEUS is a safe technique; however, given the very small likelihood of adverse reactions, resuscitation equipment should be available in every US Department where CEUS examinations are performed.

\section{Clinical applications}

\section{Native aorta}

The term abdominal aortic aneurysm (AAA) refers to an irreversible enlargement of the abdominal aorta of more than $3 \mathrm{~cm}$ or $50 \%$ of reference diameter [10]. US is excellent for screening or diagnostic evaluation and follow-up of AAA with high sensitivity and specificity and excellent intra- and inter-observer agreement [11]. The use of UCA adds little to the evaluation of an uncomplicated AAA, although it will readily and accurately delineate mural thrombus and differentiate this from slow blood flow, often not visualized with conventional US techniques $[1,4,12,13]$. Rupture of an AAA; associated with high mortality, necessitates early and accu- rate diagnosis with immediate treatment [10, 14]. Rupture risk increases with increasing aneurysm diameter rising to $>30 \%$ for aneurysms larger than $7 \mathrm{~cm}[10]$. Patients presenting with abdominal pain of acute onset and low blood pressure or decrease of hematocrit may signify an AAA rupture, and US can exclude the presence of an AAA. US has limited accuracy for detection of rupture, [15]. The use of UCA significantly increases the sensitivity for detection of several findings of AAA rupture. With the intravascular nature of the UCA, CEUS is able to visualize active extravasation and dependent pooling of the UCA in the retroperitoneum or peritoneal cavity. Although these findings closely correlate with those provided by CTA, CEUS has the potential to be performed at the bedside in the Emergency Department, prompting accurate diagnosis with earlier treatment $[16,17]$.

AAA rupture may rarely be complicated by the formation of an aorto-caval fistula, which needs specific management. Although CTA is the reference method for the evaluation of aorto-caval communications, CEUS has the potential to delineate such communication with high accuracy in a real-time and dynamic manner [18, 19]. Arterial-venous communications have also been demonstrated with UCA in different vascular systems including the femoral vessels [4].

Dissection usually affects both thoracic and abdominal aorta, with isolated abdominal aortic dissection being rare [20]. Symptoms like asymmetric blood pressure, pain of acute onset, and signs of organ dysfunction secondary to ischemia should point toward the diagnosis

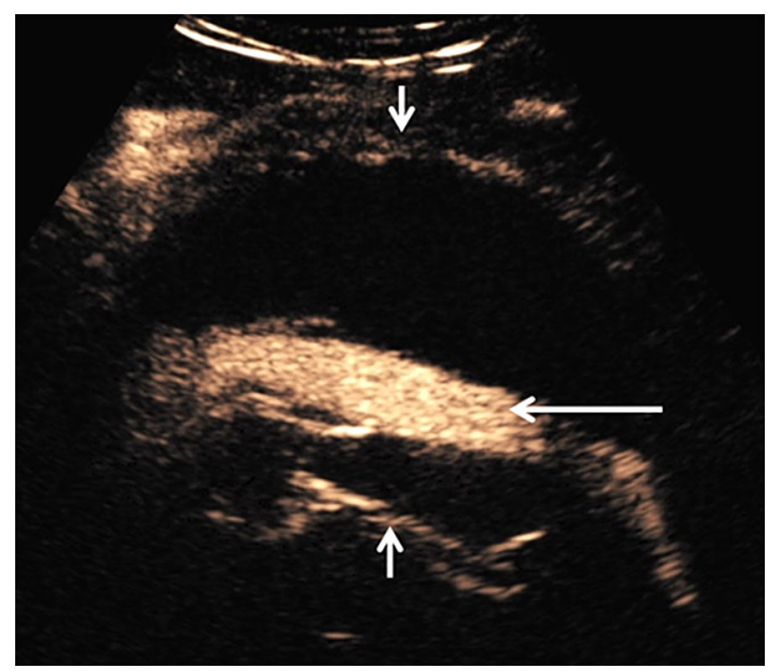

Fig. 1. Routine post-elective EVAR follow-up scan from a 83-year-old man showed an expanding aneurysmal sac. CEUS was performed to look for endoleak. Longitudinal view of an aortic stent graft within the dilated aneurysm sac (between short arrows). CEUS image demonstrates microbubble ultrasound contrast within the patent aortic stent graft with no evidence of "endoleak" (long arrow). 
of aortic dissection [21, 22]. CTA remains the primary modality for emergency evaluation of the whole aorta including the iliac arteries. If US findings are inconclusive but suspicious of dissection, UCA can be used. Suspicious conventional US findings include an intimal flap and bidirectional color flow signals within the lumen of aorta. The administration of UCA readily and accurately visualizes intimal flaps, establishing the diagnosis of dissection. Moreover, CEUS helps identify re-entry points and discriminate true and false lumen as the enhancement of the former precedes that of the later [13, 19, 23-25].

\section{Post-operative aorta}

An endovascular approach using vascular stents (Endovascular Aneurysm Repair, EVAR) is largely replacing the traditional open surgical repair of AAA. The endovascular approach needs lifelong imaging surveillance allowing for early detection and management of complications. EVAR complications include endoleak, fractures, graft migration, graft disconnection, or progressive enlargement of the aneurysmal sac. Imaging surveillance is routinely performed with CTA or US and is advocated lifelong although increased risk for rupture occurs for the first two to three years after EVAR [2630]. US is limited by low sensitivity for flow visualization while CTA is disadvantaged by iodinated contrast medium and ionizing radiation. CTA provides "snapshots" of blood flow within a stented aorta, whereas CEUS is characterized by increased sensitivity compared to US, with continuous scanning of the aneurysmal sac in a dynamic and real-time pattern, for $>3 \mathrm{~min}$ (Fig. 1). This is useful for characterization of both fast-flowing and slow-flowing endoleaks. With real-time visualization and the option to disrupt the UCA and observe the replenishment pattern, CEUS can accurately characterize the origin of the endoleak, direction, and extent; information essential for type differentiation [4, 31].

Endoleaks represent the presence of blood flow within the aneurysmal sac but outside the stented vessel lumen and characterized based on the direction of blood flow into five categories [26, 29, 32]. Type 1 endoleak refers to an endoleak originating from the attachment of the stent graft with the aortic wall; being proximal (type 1A) or distal (type 1B) attachment. Type 2 endoleaks are the most frequent and represent retrograde blood flow from an anastomotic branch of the aorta or iliac arteries into the aneurysmal sac. Such anastomotic branches are usually the inferior mesenteric or the lumbar arteries. If only one vessel is leaking, the endoleak is classified as type $2 \mathrm{~A}$, whereas if multiple vessels are implicated, the endoleak is classified as type $2 \mathrm{~B}$. Even though this endoleak usually resolves spontaneously, increased awareness is necessary as increased blood flow and pressure may lead to aneurysm sac enlargement and eventually rupture $[26,29,30]$. Structural failure of the stent may lead to type 3 endoleak, which describes blood flow originating from a defect in the stent, the frequency of this endoleak being proportionate to the stent's age [26, 29, 33] (Fig. 2; Online Resources 1, 2, 3). Type 4 endoleaks results from porosity of the stent wall, immediately after stent placement or up to 30 days after intervention (Fig. 3). Type 4 endoleaks constitute a diagnosis of exclusion, will usually resolve with normalization of coagulation parameters; carrying no clinical consequence. However, careful characterization is needed as this may mimic other types of endoleaks [26, 29]. The term endotension refers to the enlargement of aneurysm sac without a detectable endoleak, found after a successful EVAR. Endotension is also characterized as type 5 endoleak and is considered to be caused by continuously increased blood pressure within the aneurysm stent $[26,29]$.

US offers a cost effective, well-tolerated option for imaging surveillance of the post-EVAR aorta, but limited by body habitus, operator experience, and technical artifacts. The diagnostic accuracy varies; studies reporting a $45 \%$ positive predictive value and $86 \%$ sensitivity for endoleak detection [34] with US detecting more endoleaks requiring intervention compared to $\mathrm{CT}$, with a $90 \%$ sensitivity and $81 \%$ specificity [35], compared to color Doppler with a sensitivity of 33\%-63\% and specificity of $63 \%-93 \%[36,37]$.

CEUS has been widely investigated for accuracy in detecting endoleaks. Optison ${ }^{\mathrm{TM}}$ (Mallinckrodt, St Louis, Mo) was found to accurately classify endoleaks as type 1 or 2, enabling US to detect more endoleaks than delayedphase CTA [38]. The diagnostic accuracy of CEUS with Optison ${ }^{\mathrm{TM}}$ for the diagnosis of endoleaks is reported at a sensitivity of $100 \%$ and specificity of $65 \%$ [39]. CEUS with SonoVue ${ }^{\mathrm{TM}}$ has demonstrated variable results, with a sensitivity of $80 \%-100 \%$ and a specificity of $82 \%-100 \%$ in diagnosing endoleaks, outperforming color Doppler US [36, 37, 40-42]. Some studies have concluded that CEUS may even outperform CTA, the current gold standard for evaluation of endoleaks, primarily attributable to the dynamic and real-time nature of imaging [42]. According to a meta-analysis, CEUS pooled sensitivity and specificity for diagnosis of endoleak is $91.4 \%$ and $78.2 \%$, respectively, although significant heterogeneity of studies was noted, potentially limiting the accuracy for specificity [43]. Beyond subjective assessment of endoleak presence, CEUS also provides the potential for objective quantitative analysis of aneurysmal sac enhancement. Studies using time-intensity curves have demonstrated that CEUS is $99 \%$ sensitive and 93\% specific for detection of endoleaks, compared with CTA, with a significant difference between the enhancement level of aneurysms with and without endoleak [44]. If a four-dimensional technique is applied, CEUS has equivalent accuracy to CTA for 

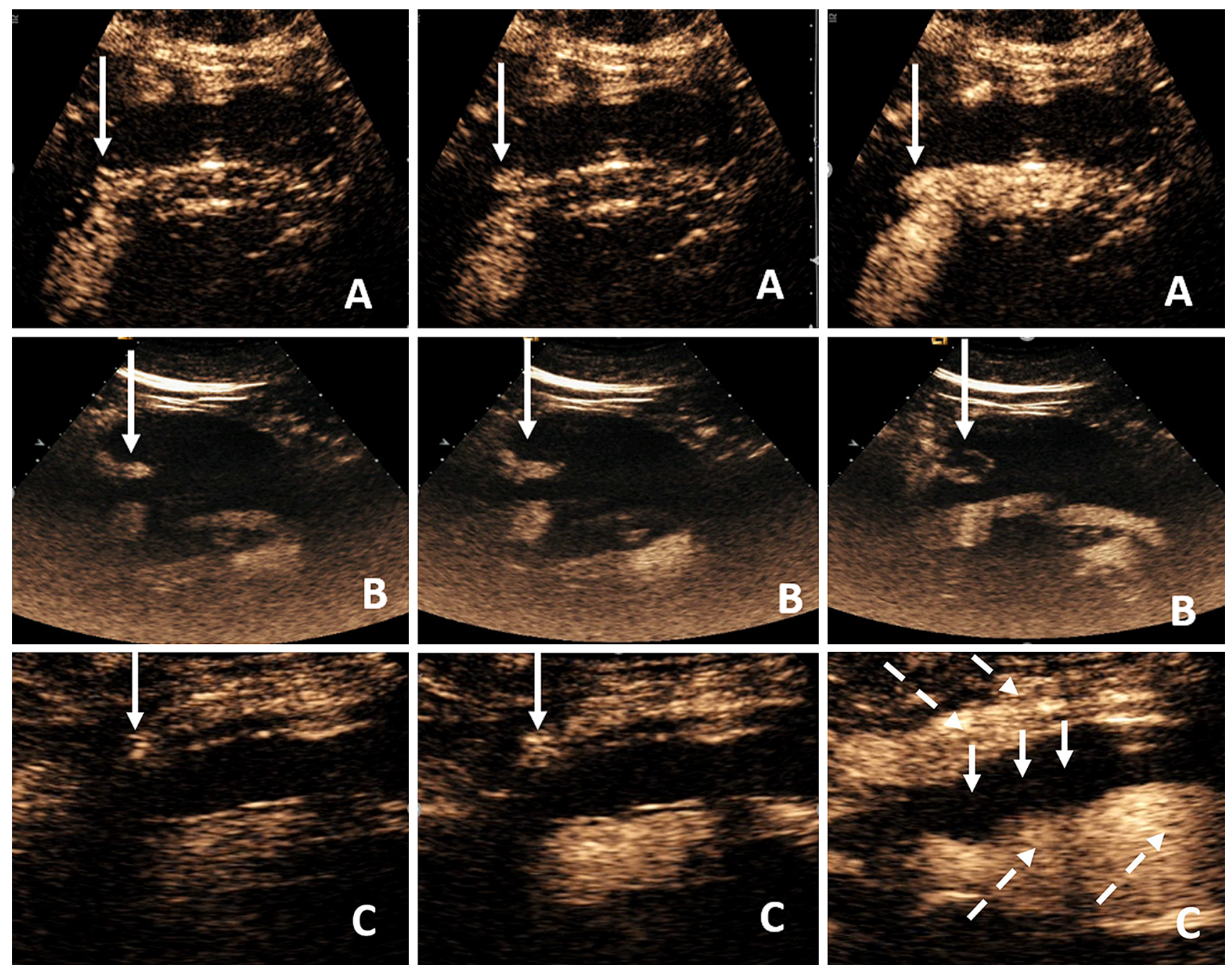

Fig. 2. Longitudinal views of aortic stent grafts demonstrates type 1 (row $\mathbf{A}$ ), type 2a (row B), and type 3 (row $\mathbf{C}$ ) endoleaks. Each row consists of sequential CEUS images (left to right) demonstrating UCA jets (long arrows) originating from the aortic stent grafts from ineffective proximal seal (row
A, type 1), persistent filling of the aneurysmal sac from the inferior mesenteric artery (row B, type 2a), and inadequate sealing of the overlapping main aortic body and iliac stent (row C, type 3). The aneurysmal sac is filled with UCA (broken arrows) with central thrombosis (short arrows).
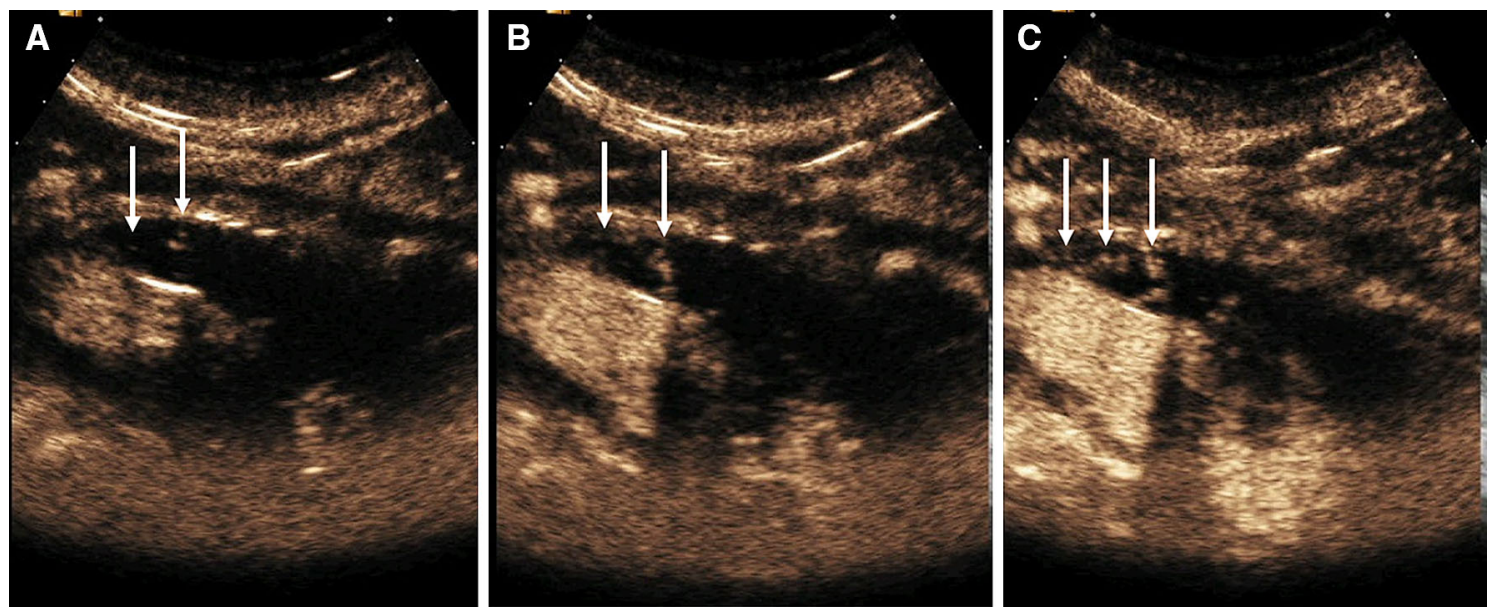

Fig. 3. Longitudinal views of aortic graft. Sequential CEUS images (A-C) demonstrates UCA jets (arrows) originating through the stent graft resulting in a type 4 endoleak due to porosity of the stent graft fabric. 
evaluation of post-operative aortic aneurysm diameter, volume, and endoleak detection in patients with fenestrated endografts [45]. According to a systematic review, CEUS and MRA have superior diagnostic accuracy compared to CTA for identification of post-EVAR endoleaks, although being equivalent to CTA for characterization of endoleaks type 1 and 3 [46]. CEUS was also found to outperform CTA for the diagnosis of delayed type II endoleak [43].

In conclusion, CEUS offers a beneficial alternative to CTA especially for patients with impaired renal function. Moreover, CEUS is also a suitable alternative for younger patients with EVAR reducing the cumulative exposure to ionizing radiation, with the need for lifelong imaging surveillance with CTA. CEUS could be incorporated in diagnostic algorithms for the detection of endoleak as a second step after initial US examination, in order to increase the technique's diagnostic accuracy. In cases of negative results, the patient could be safely discharged and referred for follow-up imaging. Further imaging with CTA could be reserved for cases with positive results or continued suspicion of endoleak [28, $31,36,47]$.
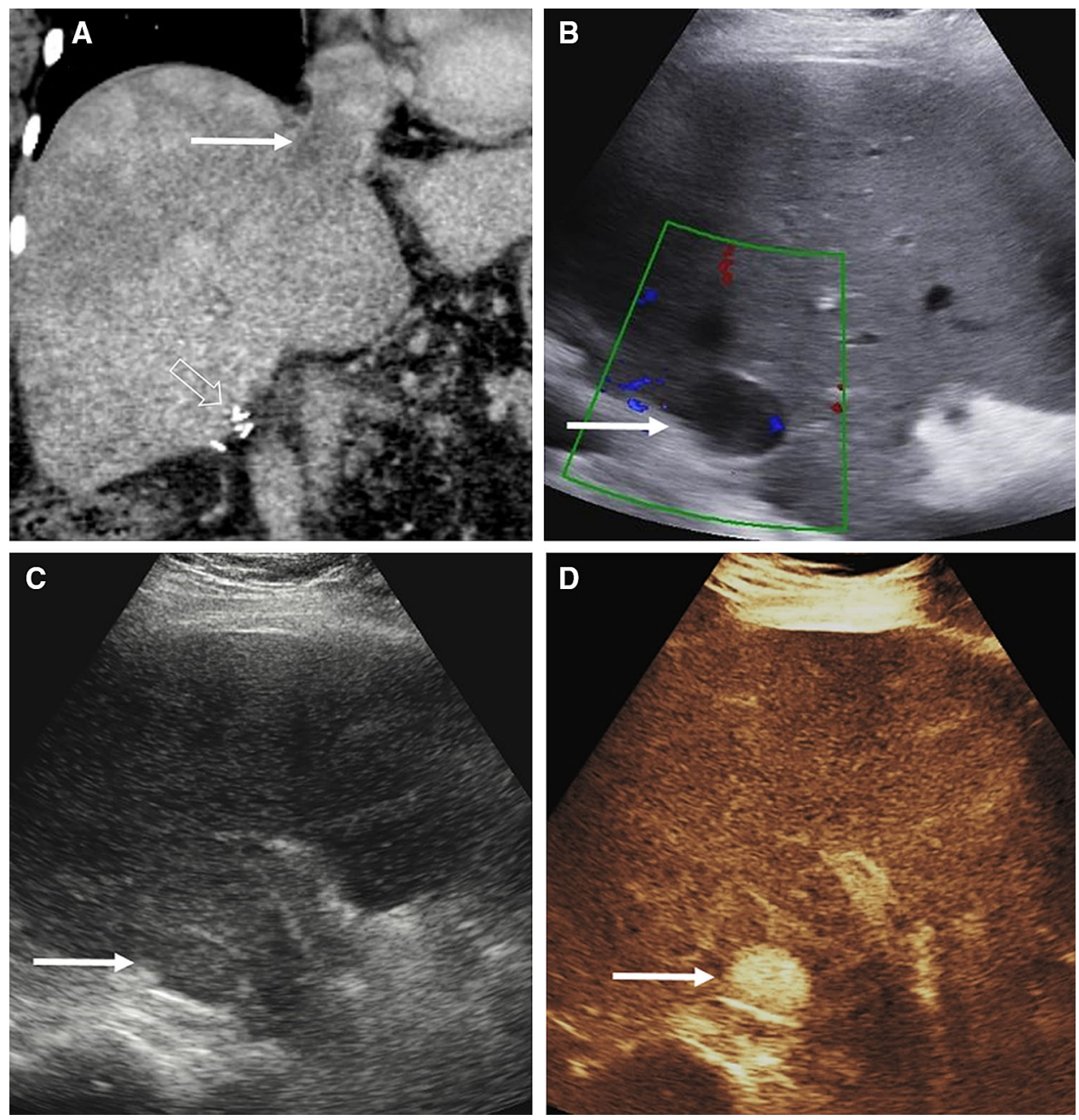

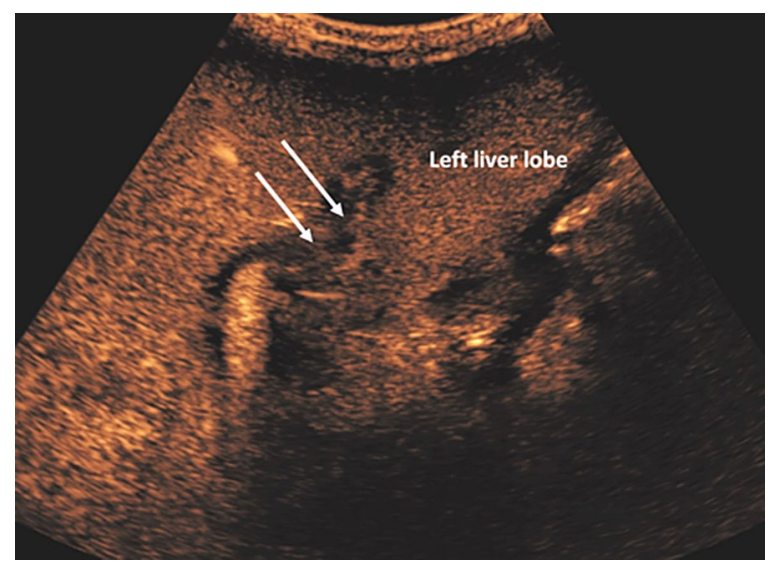

Fig. 5. CEUS image demonstrates non-occlusive bland thrombosis of the left portal vein (arrows).

\section{Portal vein thrombosis}

Portal vein thrombosis may be bland or neoplastic, in patients with hepatocellular carcinoma and cirrhosis. Accurately characterizing portal vein thrombus as neoplastic or bland is of clinical significance as the former constitutes a contraindication for liver transplantation.
Fig. 4. Patient with history of invasive retroperitoneal sarcoma compressing on IVC which was resected (surgical clips, open arrow). She subsequently presented with bilateral lower limb pitting edema. Imaging studies were performed to exclude IVC thrombus (A) coronal CECT (B) Color Doppler US and (C) Gray-scale US demonstrate near occlusive thrombus within the IVC (arrows). (D) The thrombus shows enhancement with microbubble ultrasound contrast imaging in keeping with tumor thrombus (arrow). 

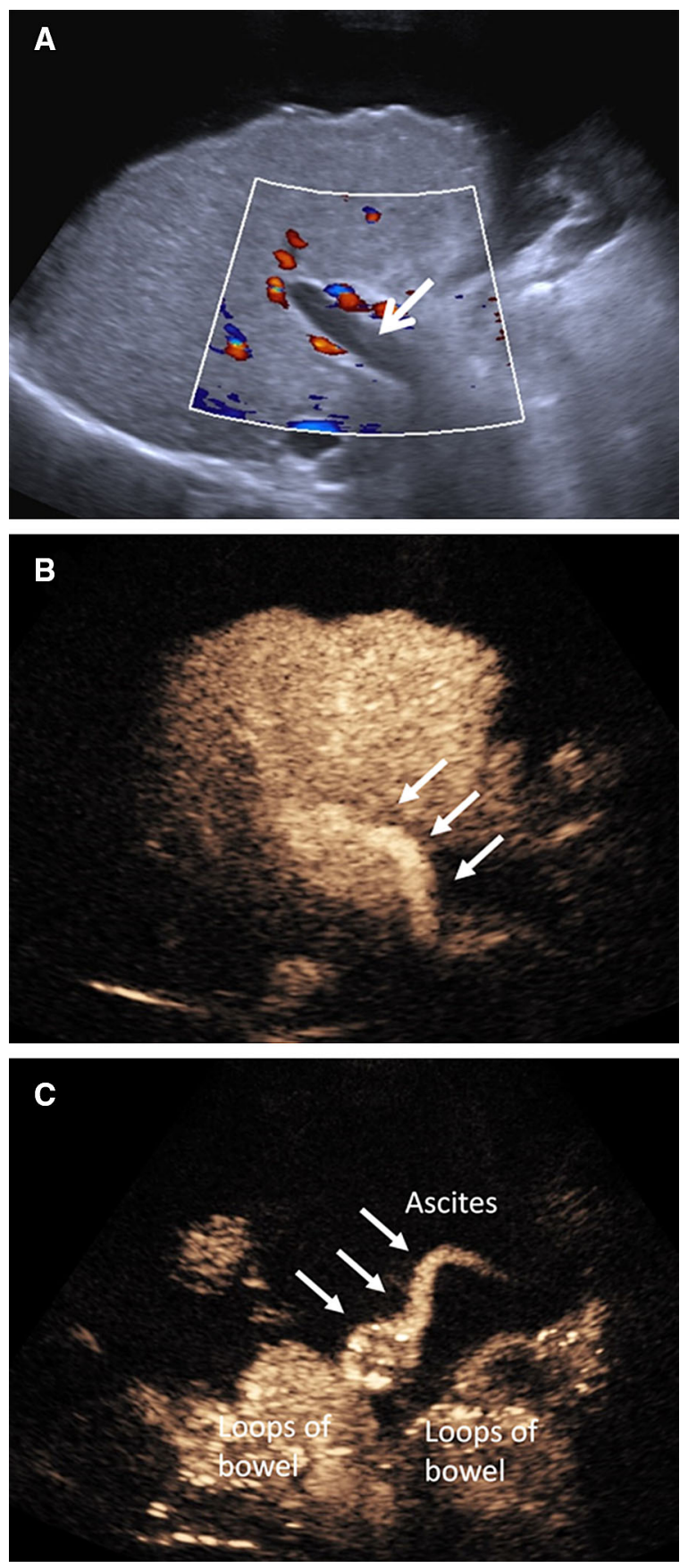

Fig. 6. A 66-year-old male with liver cirrhosis developed hepatorenal syndrome. Color Doppler US failed to demonstrate the presence of portal flow likely due to slow flow $(\mathbf{A}$, arrow). CEUS was performed instead of CECT due to poor renal function. CEUS demonstrated a patent portal vein (B, arrows). Isolated CEUS image from the same patient shows recanalisation of large umbilical vein ( $\mathbf{C}$, arrows) surrounded by large volume ascites (black area) in keeping with established portal hypertension.

Characterization of thrombus as neoplastic can be established on the presence of neovascularization within the thrombotic material. Benign thrombosis manifests with shrinkage of the thrombus or recanalization of the portal vein, seen with color Doppler US, on follow-up examination, whereas increase in thrombus size, disruption of the vessel wall, and infiltration of the adjacent liver parenchyma is in keeping with malignancy [48]. B-mode US is useful in detecting portal vein thrombosis but is unreliable in differentiating benign from malignant thrombus. Color Doppler US can be useful by demonstrating color flow signals within the thrombus although less effectively for small thrombus. A deep location of the portal vein and a potentially unfavorable body habitus may limit sensitivity for detection of neovascularization. CEUS is superior to color Doppler technique for the diagnosis of neoplastic portal vein thrombosis in patients with liver cirrhosis. CEUS has the ability to visualize pulsatile enhancement of portal vein thrombus during the arterial phase, preceding portal lumen enhancement, representing malignant neovascularization [49-54]. CEUS provides conclusive outcomes in $>97 \%$ of patients examined, with no further imaging required [51]. In terms of diagnostic accuracy, CEUS was found to be $100 \%$ sensitive, $66.7 \%$ specific, and $93.3 \%$ accurate in the diagnosis of malignant portal venous thrombosis [48]. With the introduction of CEUS in the diagnostic strategy of malignant portal vein thrombosis, fewer interventional fine-needle biopsies are required, which is considered the reference method, and less well-tolerated by the patients [53]. CEUS can also be used to characterize thrombus within other abdominal veins like the hepatic and inferior vena cava (Fig. 4). Moreover, it can accurately detect non-occlusive portal vein thrombus (Fig. 5) and establish the patency of portal vein in cases with slow flow not visualized on color Doppler technique (Fig. 6).

\section{Abdominal trauma}

CEUS in abdominal trauma has been evaluated with promising results. Traumatic parenchymal lesions appear as non-enhancing hypoechoic areas and showing variance with the otherwise normally perfused parenchyma. CEUS can readily identify and characterize lacerations, contusions, and intra-parenchymal or sub-capsular hematomas affecting all solid organs of the abdominal cavity. Based on studies comparing US and CEUS with CT as the reference standard in patients sustaining blunt abdominal trauma, CEUS was found to outperform US in terms of sensitivity and specificity for the diagnosis of solid organ injury, with CEUS demonstrating 69\% sensitivity and $99 \%$ specificity for diagnosing renal trauma, $84 \%$ sensitivity and $99 \%$ specificity for liver trauma, and $93 \%$ sensitivity and $99 \%$ specificity for splenic trauma $[1$, $55,56]$.

Beside characterization of parenchymal injuries, CEUS is particularly valuable for detection of vascular abnormalities not visualized with the unenhanced 

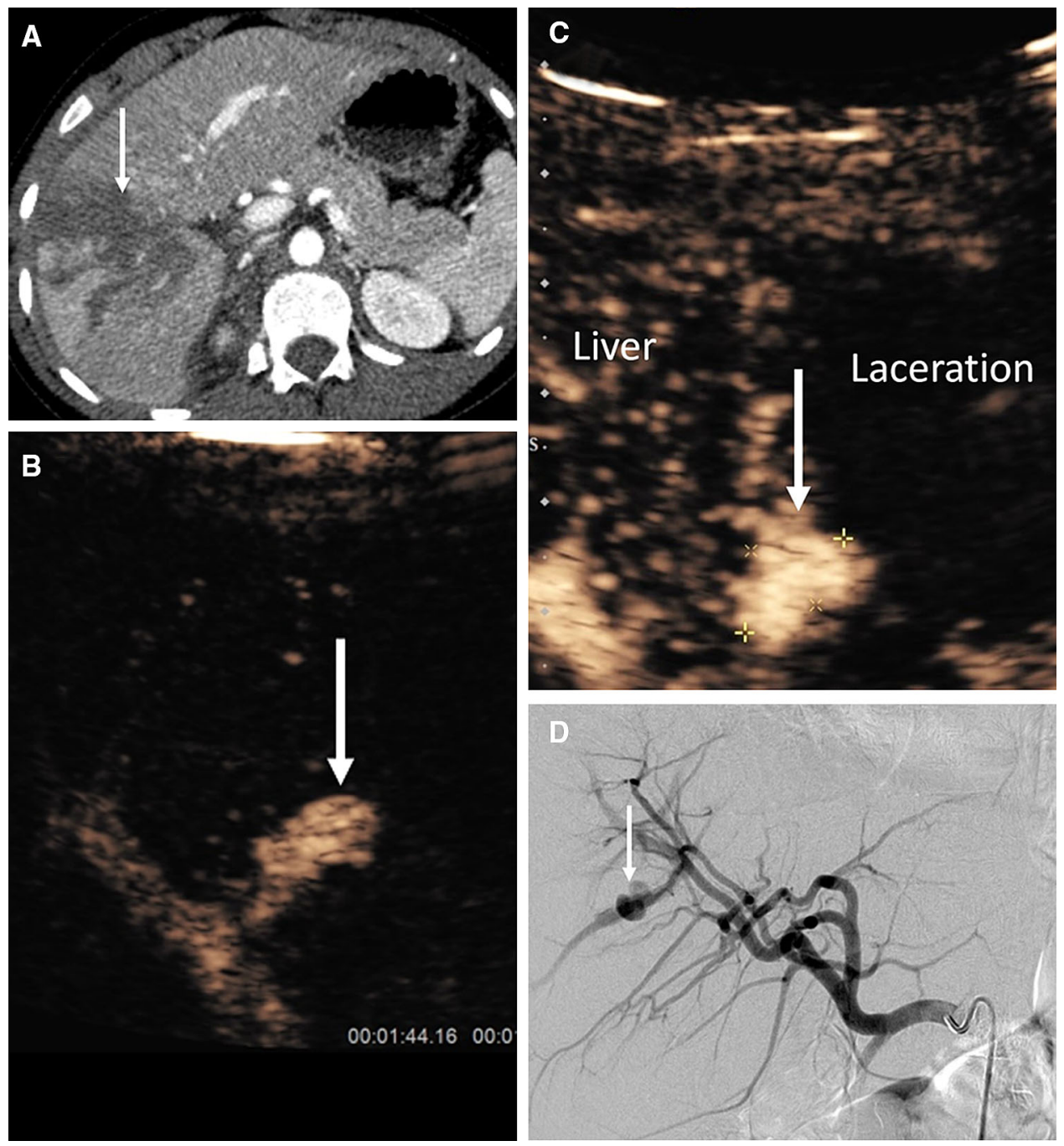

Fig. 7. A 14-year-old boy fell downstairs and sustained a grade 4 liver laceration. CECT (axial) shows linear area of liver laceration (A, arrow). CEUS of the liver was performed 5 days post-trauma to evaluate the injury.

Sequential CEUS images (B and $\mathbf{C}$ ) demonstrate a pseudoaneurysm (arrow in $\mathbf{B}$, between cursors and arrow in $\mathbf{C}$ ). Image $\mathbf{B}$ is taken during arterial phase akin to the CT angiographic phase with microbubble contrast only seen in the hepatic artery and pseudoaneurysm. The later image $\mathbf{C}$ shows the presence of microbubble contrast within the liver. The part of the liver which lacks microbubble contrast correspond to area of liver laceration. The pseudoaneurysm was confirmed during conventional hepatic artery catheter angiography (D, arrow) and subsequently successfully embolized with vascular coils.
B-mode US. These abnormalities include parenchymal infarcts, arterial pseudoaneurysms, and active hemorrhage [1, 56, 57] (Fig. 7). The extravasation of UCA represents foci of active hemorrhage and has been reported in splenic, liver, and renal trauma. UCA extravasation may be visualized as rounded echogenic pools or as fountain-like echogenic jets [17].

\section{Transplantation}

US is routinely performed for monitoring of transplanted organs during the post-operative period for early detection of complications, including arterial occlusion or stenosis and venous thrombosis. The unenhanced techniques of B-mode, color Doppler, and spectral analysis are an invaluable tool for screening for these complications. However, sensitivity is limited with inconclusive results. Further imaging is often warranted either with a non-invasive type of angiography (CTA or MRA) or with interventional angiography. CEUS is well-established for the evaluation of both micro-vascu- lature and macro-vasculature, acting as a potential alternative to CTA or MRA.

It has been established that the administration of UCA increases the diagnostic accuracy of US for the detection of ischemic areas of both native and transplanted organs, demonstrating areas of ischemia with increased tissue contrast, depicted as non-enhancing areas within the normally perfused parenchyma. Color Doppler provides only a subjective assessment of tissue vascularity based on the color flow signals [58-61].

CEUS is useful for assessment of liver transplantation complications including hepatic artery and portal vein occlusion and stenosis, active hemorrhage, pseudoaneurysm formation, and parenchyma infarction. The intravenous administration of UCA provides real-time evaluation of tissue perfusion and detailed vascular opacification, offering greater confidence for the performing physician and facilitating the visualization of patent, occluded, or stenotic hepatic arteries (Fig. 8). CEUS may obviate the need for interventional angiography in $>60 \%$ of patients [62-66] and is $92.3 \%$ sensi- 

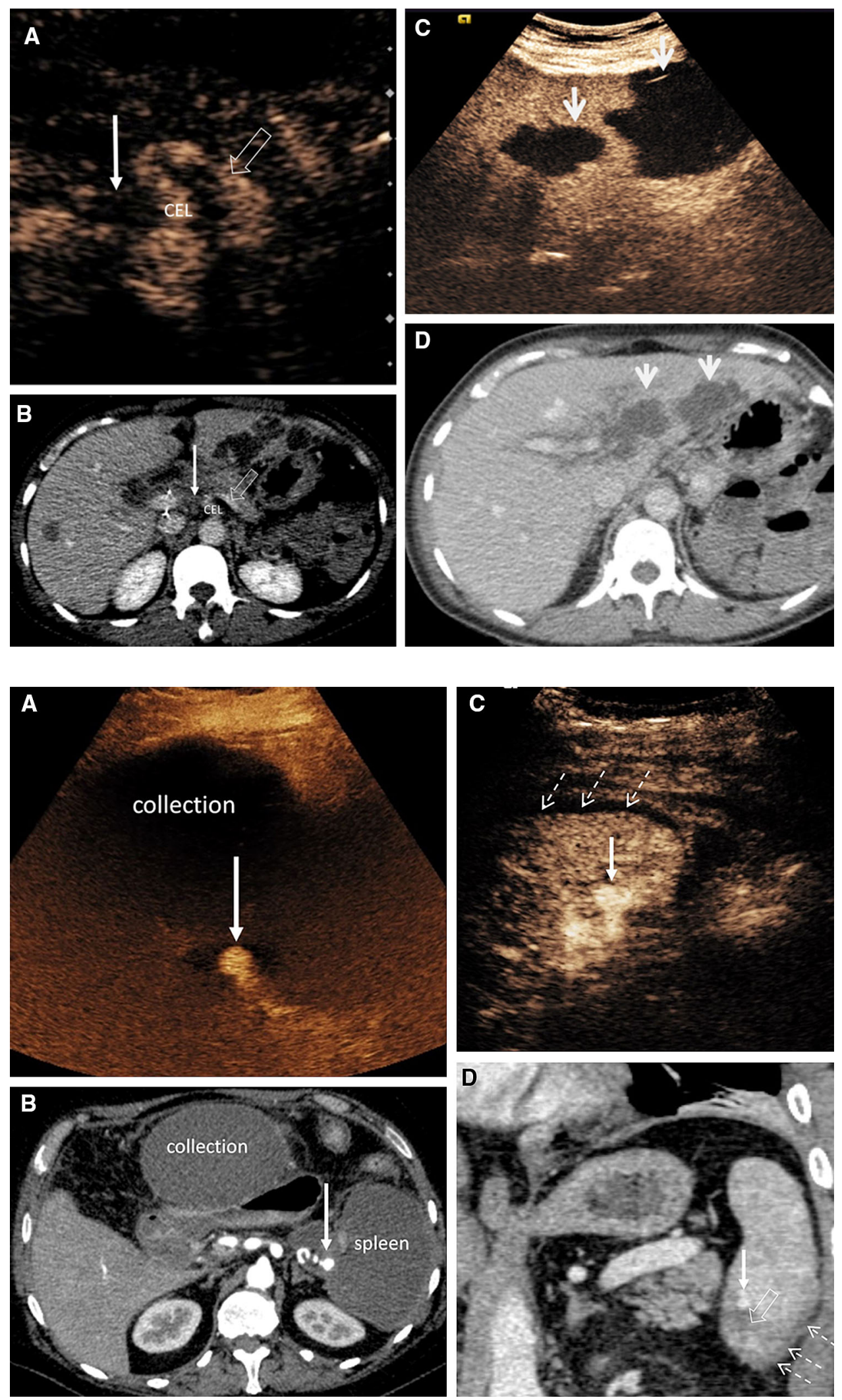

Fig. 8. A 60-year-old female developed hepatic artery thrombosis post-liver transplantation. The CEUS

(A) and axial CECT

(B) comparison images demonstrate proximal hepatic artery thrombosis (solid arrow) with lack of microbubble ultrasound contrast or iodinated contrast vascular enhancement. The coeliac trunk is labeled as CEL and the splenic artery is indicated by open arrows. There is widespread resultant geographical areas of hepatic infarction present on the CECT and CEUS images (arrows, C and D).

Fig. 9. CEUS and CECT images from two cases of splenic artery pseudoaneurysm formation (arrows). A (CEUS) and B (CECT, axial) from a 47-year-old male who developed splenic artery pseudoaneurysm encased by necrotising pancreatitis with large peripancreatic collection and completely infarcted non-enhancing spleen. C (CEUS) and D (CECT, coronal) from a 43-year-old male who suffered blunt abdominal trauma demonstrates a small peri-splenic hematoma (broken arrows) and a pseudoaneurysm (arrow) adjacent to the laceration (open arrow). tive and $87.5 \%$ specific for the diagnosis of hepatic artery stenosis, correcting false-positive results found on color Doppler. CEUS may be introduced in a diagnostic algorithm following color Doppler US for evaluation of liver transplant vasculature, with positive findings on CEUS warranting investigation with angiography [67]. 

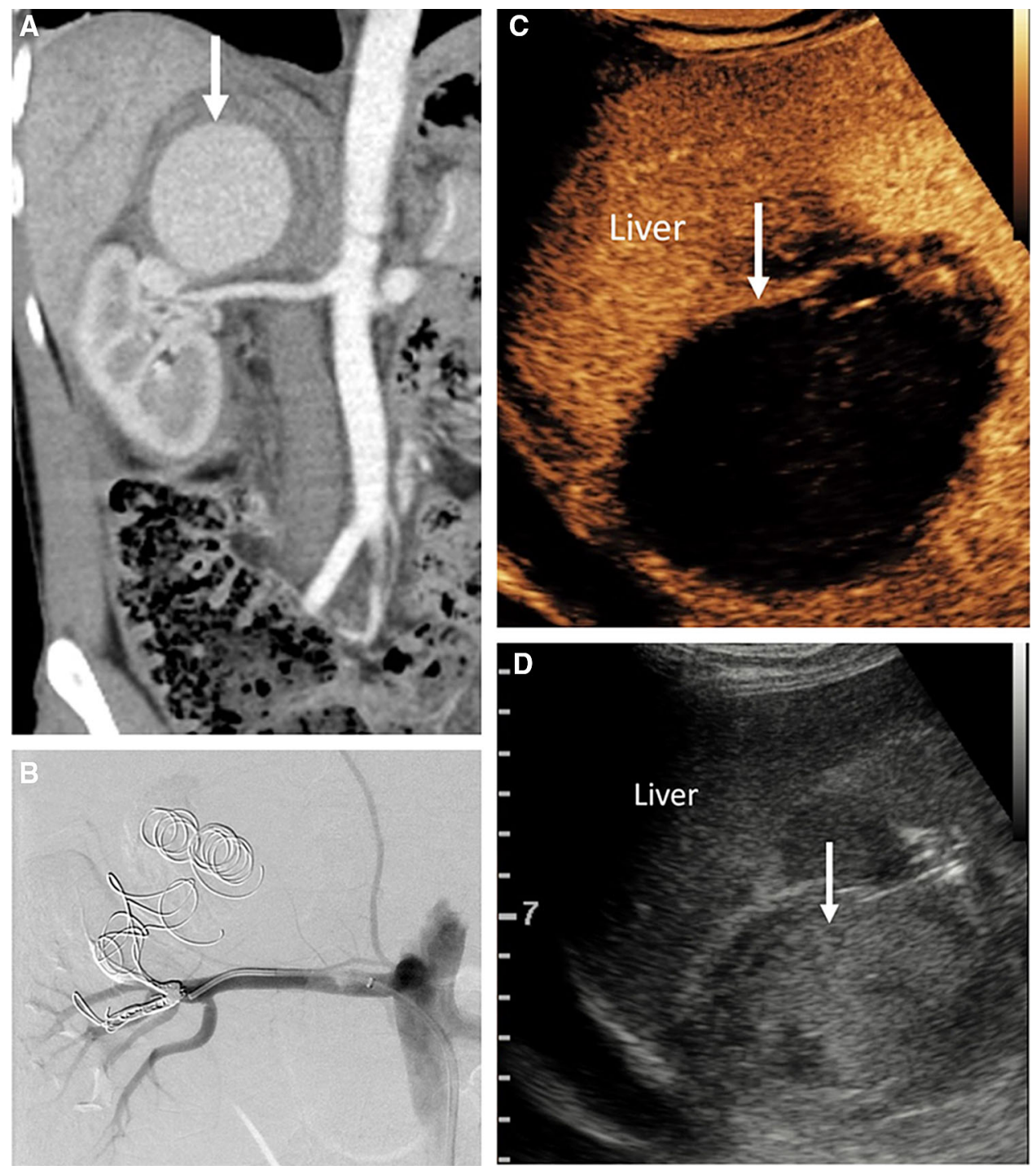

Fig. 10. Images from a 40-year-old male with suspected renal colic. Coronal CECT (A) shows a giant branch renal artery pseudoaneurysm (arrow) which was coil embolized (B). Post-procedural followup CEUS image

(C) demonstrates the absence of microbubble ultrasound contrast within the aneurysm sac (arrow) in keeping with complete occlusion of the pseudoaneurysm. Greyscale image shows echogenic thrombus within the pseudoaneurysm (D, arrow).
CEUS following renal transplantation can be used to identify acute cortical necrosis, demonstrating the peripheral rim sign, as seen on CT and MR imaging [68]. Functional information related to the transplanted kidney can be obtained with quantification of parenchymal signal intensity on CEUS. This technique produces timeintensity curves and dynamic variables like time-to-peak and peak intensity. Good inter-observer agreement was demonstrated with this type of analysis, while the quantitative variables obtained have been correlated with glomerular filtration rate 3 months after transplantation [69].

\section{Other abdominal vessels}

Renal and mesenteric arteries represent a challenging arterial system for US evaluation due to their deep location, tortuous course, and overlying bowel gas. Recent technological advances and widespread availability of CTA or MRA have replaced interventional angiog- raphy for evaluation of renal and mesenteric artery stenosis. CEUS is able to accurately detect and delineate aneurysms affecting virtually any blood vessels visualized with US (Fig. 9). Moreover, CEUS may play an important role in the post-interventional management of such patients; identifying residual flow within aneurysms or establishing their successful embolization (Fig. 10). The use of UCA may be expected to increase accuracy for evaluation, but there is limited literature available [1].

The administration of Levovist ${ }^{\mathrm{TM}}$ (Schering, AG, Berlin), a first-generation UCA, allowed for quicker evaluation of intrarenal arteries Doppler spectrum with superior sensitivity and specificity compared to the unenhanced technique [70]. The administration of UCA can be used to aid correct placement of the sample volume during pulsed-wave Doppler interrogation of the renal arteries, increasing the technique's sensitivity [71]. Similarly, CEUS with Levovist ${ }^{\mathrm{TM}}$ was also found superior to the unenhanced color Doppler technique, showing excellent agreement with interventional angiography 

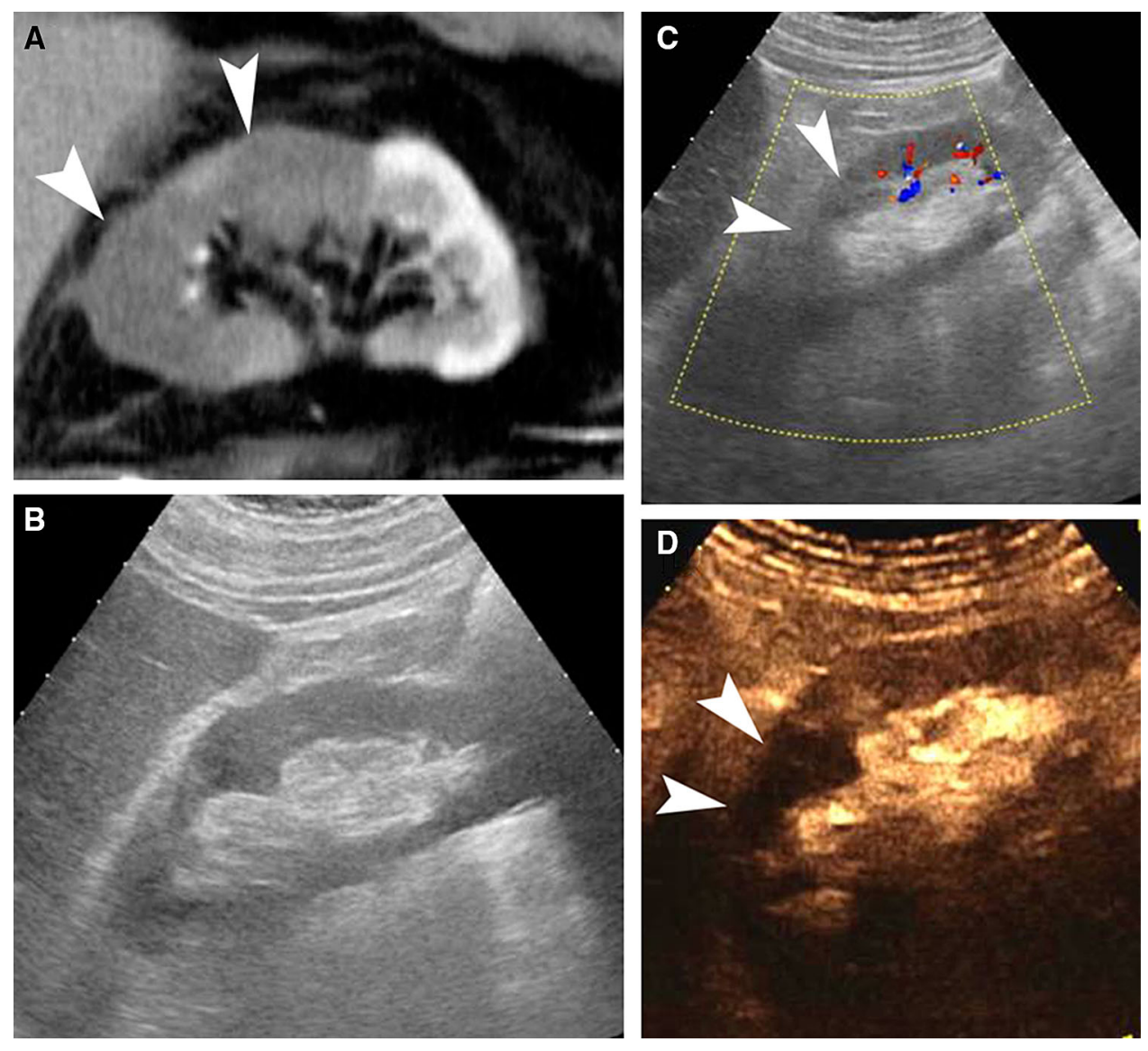

Fig. 11. Imaging findings in a patient with renal infarction. Oblique sagittal MDCTA image (A) showing the kidney in long-axis, revealed the presence of an upper pole renal infarct (arrowheads). On follow-up US, long-axis B-mode technique (B) did not visualize any significant alterations in parenchymal echogenicity. Respective color Doppler technique image (C) demonstrated less blood flow signals on the upper half of the kidney (arrowheads), in keeping with the infarct. Respective CEUS image (D) readily confirmed the diagnosis of renal infarction (arrowheads). for grading renal artery stenosis [72]. Evaluation of renal parenchyma perfusion with CEUS is superior to the unenhanced color Doppler technique and almost equivalent to contrast-enhanced CT, based on the increased tissue contrast achieved between viable and ischemic tissue, primarily a consequence of the truly intravascular nature of the UCA $[1,58]$. Renal parenchymal infarction appears on CEUS as hypoechoic non-enhancing wedgeshaped areas, readily differentiated from cortical necrosis [1, 59] (Fig. 11).

The use of UCA for the evaluation of other aortic branches is limited to the superior and inferior mesenteric artery. Definity ${ }^{\mathrm{TM}}$ (Lantheus Medical Imaging, Billerica, Massachusetts) offers increased sensitivity for the identification of celiac and mesenteric artery stenosis and occlusion [73]. Others have investigated the use of UCA for evaluation of mesenteric transit time in Crohn's disease, and even though visual and software-based assessment of the time of maximum UCA enhancement in the superior mesenteric artery and vein correlated well, there was no significant correlation with disease activity [74].

CEUS has also been used to detect liver metastasis by evaluating hepatic artery and vein enhancement based on the arrival times to hepatic artery and vein and transit time between artery and vein; shorter with an increased level of enhancement in both vessels in patients with liver metastases. Based on these results, a functional ultrasonographic technique performed with only $0.6 \mathrm{~mL}$ of SonoVue ${ }^{\mathrm{TM}}$ can be used to detect micrometastases in the liver [75].

\section{Conclusion}

The introduction of UCA has significantly expanded the role of US in the investigation of abdominal vascular diseases. CEUS is superior to conventional US techniques in term of tissue contrast, spatial, and temporal resolution and its dynamic and real-time nature in assessment of tissue perfusion and vascular lumen opacification. Experience has shown that CEUS plays a key role in certain clinical scenarios such as evaluation of abdominal trauma, diagnosis of organ ischemia, imaging surveillance of post-EVAR aorta or the differential diagnosis of malignant vs. benign portal vein thrombosis in patients with liver cirrhosis and hepatocellular carcinoma. CEUS is also useful in assisting ultrasonographic evaluation of other blood vessels, although the widespread availability of CTA and MRA has limited its role in the renal arteries and mesenteric arteries. 


\section{Compliance with ethical standards}

Funding Not applicable.

Conflict of interest Authors VR and CF declare that they have no potential conflict of interest. Author GY has received lecture fees from Bracco. Author DH has received fees from Bracco for providing a training workshop on CEUS. Author PS has received lecture fees from Bracco, Siemens, Samsung, Philips, and Hitachi.

This article does not contain any studies with human participants or animals performed by any of the authors.

Open Access This article is distributed under the terms of the Creative Commons Attribution 4.0 International License (http://creativecommons. org/licenses/by/4.0/), which permits unrestricted use, distribution, and reproduction in any medium, provided you give appropriate credit to the original author(s) and the source, provide a link to the Creative Commons license, and indicate if changes were made.

\section{References}

1. Piscaglia F, Nolsoe C, Dietrich CF, et al. (2012) The EFSUMB guidelines and recommendations on the clinical practice of contrast enhanced ultrasound (CEUS): update 2011 on non-hepatic applications. Ultraschall Med 33:33-59. doi:10.1055/s-0031-1281676

2. Sidhu PS (2015) Multiparametric ultrasound (MPUS) imaging: terminology describing the many aspects of ultrasonography. Ultraschall Med 36:315-317. doi:10.1055/s-0035-1553381

3. Barr RG (2017) How to develop a contrast-enhanced ultrasound program. J Ultrasound Med 36:1225-1240. doi:10.7863/ultra. 16.09045

4. Rubenthaler J, Reiser M, Clevert DA (2016) Diagnostic vascular ultrasonography with the help of color Doppler and contrast-enhanced ultrasonography. Ultrasonography 35:289-301. doi: 10.14366/usg. 16027

5. Piscaglia F, Bolondi L, Italian Society for Ultrasound in M, Biology Study Group on Ultrasound Contrast A (2006) The safety of Sonovue in abdominal applications: retrospective analysis of 23188 investigations. Ultrasound Med Biol 32:1369-1375. doi:10.1016/ j.ultrasmedbio.2006.05.031

6. Cantisani V, Wilson SR (2015) CEUS: where are we in 2015? Eur J Radiol 84:1621-1622. doi:10.1016/j.ejrad.2015.05.028

7. Parker JM, Weller MW, Feinstein LM, et al. (2013) Safety of ultrasound contrast agents in patients with known or suspected cardiac shunts. Am J Cardiol 112:1039-1045. doi:10.1016/j.amj card.2013.05.042

8. Prince MR, Zhang H, Zou Z, Staron RB, Brill PW (2011) Incidence of immediate gadolinium contrast media reactions. AJR Am J Roentgenol 196:W138-W143. doi:10.2214/ajr.10.4885

9. Wang CL, Cohan RH, Ellis JH, et al. (2008) Frequency, outcome, and appropriateness of treatment of nonionic iodinated contrast media reactions. AJR Am J Roentgenol 191:409-415. doi:10.2214/ ajr.07.3421

10. Kent KC (2014) Clinical practice. Abdominal aortic aneurysms. N Engl J Med 371:2101-2108. doi:10.1056/NEJMcp1401430

11. Singh K, Bonaa KH, Solberg S, Sorlie DG, Bjork L (1998) Intra- and interobserver variability in ultrasound measurements of abdominal aortic diameter. The Tromso Study. Eur J Vasc Endovasc Surg 15: 497-504

12. Clevert DA, Schick K, Chen MH, Zhu QL, Reiser M (2009) Role of contrast enhanced ultrasound in detection of abdominal aortic abnormalities in comparison with multislice computed tomography. Chin Med J 122:858-864

13. Schinkel AF, Kaspar M, Staub D (2016) Contrast-enhanced ultrasound: clinical applications in patients with atherosclerosis. Int J Cardiovasc Imaging 32:35-48. doi:10.1007/s10554-015-0713-Z

14. Clevert DA, Horng A, Reiser MF (2009) Ultrasound imaging of the abdominal aorta. Radiologe 49:1024-1032. doi:10.1007/s00117009-1875-2

15. Rafailidis V, Godosis D, Kouskouras K, Rafailidis D, Charitanti A (2016) Man with abdominal pain. Ann Emerg Med 68:e1-e2. doi: 10.1016/j.annemergmed.2015.11.016
16. Catalano O, Lobianco R, Cusati B, Siani A (2005) Contrast-enhanced sonography for diagnosis of ruptured abdominal aortic aneurysm. Am J Roentgenol 184:423-427. doi:10.2214/ajr.184.2. 01840423

17. Catalano O, Sandomenico F, Raso MM, Siani A (2005) Real-time, contrast-enhanced sonography: a new tool for detecting active bleeding. J Trauma 59:933-939

18. Clevert DA, Stickel M, Flach P, et al. (2007) Contrast-enhanced ultrasound in detection and follow-up of an infrarenal abdominal aortic aneurysm with aorto-caval fistula and endovascular treatment. Cardiovasc Intervent Radiol 30:480-484. doi:10.1007/ s00270-006-0143-3

19. Clevert DA, Stickel M, Johnson T, et al. (2007) Imaging of aortic abnormalities with contrast-enhanced ultrasound. A pictorial comparison with CT. Eur Radiol 17:2991-3000. doi:10.1007/s003 30-006-0542-5

20. Farber A, Wagner WH, Cossman DV, et al. (2002) Isolated dissection of the abdominal aorta: clinical presentation and therapeutic options. J Vasc Surg 36:205-210

21. Spittell PC, Spittell JA Jr, Joyce JW, et al. (1993) Clinical features and differential diagnosis of aortic dissection: experience with 236 cases (1980 through 1990). Mayo Clin Proc 68:642-651

22. Khan IA, Nair CK (2002) Clinical, diagnostic, and management perspectives of aortic dissection. Chest 122:311-328

23. Clevert DA, Stickel M, Flach P, et al. (2007) Contrast-enhanced ultrasound in detection and follow-up of an infrarenal abdominal aortic aneurysm with aorto-caval fistula and endovascular treatment. CardioVasc Interv Radiol 30:480-484. doi:10.1007/s00270006-0143-3

24. Clevert DA, Weckbach S, Kopp R, et al. (2008) Imaging of aortic lesions with color coded duplex sonography and contrast-enhanced ultrasound vs. multislice computed tomography (MS-CT) angiography. Clin Hemorheol Microcirc 40:267-279

25. Clevert DA, Horng A, Clevert DA, et al. (2009) Contrast-enhanced ultrasound vs. conventional ultrasound and MS-CT in the diagnosis of abdominal aortic dissection. Clin Hemorheol Microcirc 43:129-139. doi:10.3233/ch-2009-1227

26. Shah A, Stavropoulos SW (2009) Imaging surveillance following endovascular aneurysm repair. Sem Int Radiol 26:10-16. doi: $10.1055 / \mathrm{s}-0029-1208378$

27. White RA (2000) Endograft surveillance: a priority for long-term device performance. J Endovasc Ther 7:522. doi:10.1177/1526602 80000700616

28. Cantisani V, Grazhdani H, Clevert DA, et al. (2015) EVAR: benefits of CEUS for monitoring stent-graft status. Eur J Radiol 84:1658-1665. doi:10.1016/j.ejrad.2015.07.001

29. Pandey N, Litt HI (2015) Surveillance imaging following endovascular aneurysm repair. Sem Interv Radiol 32:239-248. doi:10.1055/s$0035-1556878$

30. Schlosser FJ, Gusberg RJ, Dardik A, et al. (2009) Aneurysm rupture after EVAR: can the ultimate failure be predicted? Eur J Vasc Endovasc Surg 37:15-22. doi:10.1016/j.ejvs.2008.10.011

31. Iezzi R, Cotroneo AR, Basilico R, et al. (2010) Endoleaks after endovascular repair of abdominal aortic aneurysm: value of CEUS. Abdom Imaging 35:106-114. doi:10.1007/s00261-009-9526-7

32. White GH, Yu W, May J (1996) Endoleak-a proposed new terminology to describe incomplete aneurysm exclusion by an endoluminal graft. J Endovasc Surg 3:124-125. doi: 10.1583/10746218(1996)003<0124b: > 2.0.CO;2

33. Baum RA, Stavropoulos SW, Fairman RM, Carpenter JP (2003) Endoleaks after endovascular repair of abdominal aortic aneurysms. J Vasc Interv Radiol 14:1111-1117

34. Manning BJ, O'Neill SM, Haider SN, et al. (2009) Duplex ultrasound in aneurysm surveillance following endovascular aneurysm repair: a comparison with computed tomography aortography. J Vasc Surg 49:60-65. doi:10.1016/j.jvs.2008.07.079

35. Schmieder GC, Stout CL, Stokes GK, Parent FN, Panneton JM (2009) Endoleak after endovascular aneurysm repair: Duplex ultrasound imaging is better than computed tomography at determining the need for intervention. J Vasc Surg 50:1012-1018. doi: 10.1016/j.jvs.2009.06.021

36. Clevert DA, Minaifar N, Weckbach S, et al. (2008) Color duplex ultrasound and contrast-enhanced ultrasound in comparison to 
MS-CT in the detection of endoleak following endovascular aneurysm repair. Clin Hemorheol Microcirc 39:121-132

37. Clevert DA, Horng A, Kopp R, et al. (2009) Imaging of endoleaks after endovascular aneurysm repair (EVAR) with contrast-enhanced ultrasound (CEUS). Radiologe 49:1033-1039. doi:10.1007/ s00117-009-1876-1

38. Bendick PJ, Bove PG, Long GW, et al. (2003) Efficacy of ultrasound scan contrast agents in the noninvasive follow-up of aortic stent grafts. J Vasc Surg 37:381-385. doi:10.1067/mva.2003.17

39. Giannoni MF, Palombo G, Sbarigia E, et al. (2003) Contrast-enhanced ultrasound imaging for aortic stent-graft surveillance. J Endovasc Ther 10:208-217. doi:10.1177/152660280301000208

40. Yang X, Chen Y-X, Zhang B, et al. (2015) Contrast-enhanced ultrasound in detecting endoleaks with failed computed tomography angiography diagnosis after endovascular abdominal aortic aneurysm repair. Chin Med J 128:2491-2497. doi:10.4103/03666999.164935

41. Dill-Macky MJ, Wilson SR, Sternbach Y, Kachura J, Lindsay T (2007) Detecting endoleaks in aortic endografts using contrast-enhanced sonography. Am J Roentgenol 188:W262-W268. doi: 10.2214/AJR.05.0532

42. Pfister K, Rennert J, Uller W, et al. (2009) Contrast harmonic imaging ultrasound and perfusion imaging for surveillance after endovascular abdominal aneurysm repair regarding detection and characterization of suspected endoleaks. Clin Hemorheol Microcirc 43:119-128. doi:10.3233/ch-2009-1226

43. Chung J, Kordzadeh A, Prionidis I, Panayiotopoulos Y, Browne T (2015) Contrast-enhanced ultrasound (CEUS) vs. computed tomography angiography (CTA) in detection of endoleaks in postEVAR patients. Are delayed type II endoleaks being missed? A systematic review and meta-analysis. J Ultrasound 18:91-99. doi: 10.1007/s40477-014-0154-x

44. Jung EM, Rennert J, Fellner C, et al. (2010) Detection and characterization of endoleaks following endovascular treatment of abdominal aortic aneurysms using contrast harmonic imaging $(\mathrm{CHI})$ with quantitative perfusion analysis (TIC) compared to CT angiography (CTA). Ultraschall Med 31:564-570. doi:10.1055/s-0028-1109811

45. Gargiulo M, Gallitto E, Serra C, et al. (2014) Could four-dimensional contrast-enhanced ultrasound replace computed tomography angiography during follow up of fenestrated endografts? Results of a preliminary experience. Eur J Vasc Endovasc Surg 48:536-542. doi:10.1016/j.ejvs.2014.05.025

46. Guo Q, Zhao J, Huang B, et al. (2016) A systematic review of ultrasound or magnetic resonance imaging compared with computed tomography for endoleak detection and aneurysm diameter measurement after endovascular aneurysm repair. J Endovasc Ther 23:936-943. doi:10.1177/1526602816664878

47. Partovi S, Kaspar M, Aschwanden M, et al. (2015) Contrast-enhanced ultrasound after endovascular aortic repair - current status and future perspectives. Cardiovasc Diag Ther 5:454-463. doi: 10.3978/j.issn.2223-3652.2015.09.04

48. Song ZZ, Huang M, Jiang TA, et al. (2010) Diagnosis of portal vein thrombosis discontinued with liver tumors in patients with liver cirrhosis and tumors by contrast-enhanced US: a pilot study. Eur J Radiol 75:185-188. doi:10.1016/j.ejrad.2009.04.021

49. Tarantino L, Francica G, Sordelli I, et al. (2006) Diagnosis of benign and malignant portal vein thrombosis in cirrhotic patients with hepatocellular carcinoma: color Doppler US, contrast-enhanced US, and fine-needle biopsy. Abdom Imaging 31:537-544. doi:10.1007/s00261-005-0150-x

50. Piscaglia F, Gianstefani A, Ravaioli M, et al. (2010) Criteria for diagnosing benign portal vein thrombosis in the assessment of patients with cirrhosis and hepatocellular carcinoma for liver transplantation. Liver Transpl 16:658-667. doi:10.1002/lt.22044

51. Danila M, Sporea I, Popescu A, Sirli R, Sendroiu M (2011) The value of contrast enhanced ultrasound in the evaluation of the nature of portal vein thrombosis. Med Ultrason 13:102-107

52. Salman S (2012) Portal vein thrombosis with contrast enhanced ultrasound in a patient with hepatocellular carcinoma: a case study. Australas J Ultrasound Med 15:67-70. doi:10.1002/j.2205-0140.2012.tb00229.x

53. Tarantino L, Ambrosino P, Di Minno MND (2015) Contrast-enhanced ultrasound in differentiating malignant from benign portal vein thrombosis in hepatocellular carcinoma. World J Gastroenterol 21:9457-9460. doi:10.3748/wjg.v21.i32.9457
54. Danila M, Sporea I, Popescu A, Sirli R (2016) Portal vein thrombosis in liver cirrhosis - the added value of contrast enhanced ultrasonography. Med Ultrason 18:218-233. doi:10.11152/mu.2013.2066.182.pvt

55. Catalano O, Aiani L, Barozzi L, et al. (2009) CEUS in abdominal trauma: multi-center study. Abdom Imaging 34:225-234. doi: 10.1007/s00261-008-9452-0

56. Valentino M, Ansaloni L, Catena F, et al. (2009) Contrast-enhanced ultrasonography in blunt abdominal trauma: considerations after 5 years of experience. Radiol Med 114:1080-1093. doi: 10.1007/s11547-009-0444-0

57. Cokkinos D, Antypa E, Stefanidis K, et al. (2012) Contrast-enhanced ultrasound for imaging blunt abdominal trauma - indications, description of the technique and imaging review. Ultraschall Med 33:60-67. doi:10.1055/s-0031-1273442

58. Bertolotto M, Martegani A, Aiani L, et al. (2008) Value of contrast-enhanced ultrasonography for detecting renal infarcts proven by contrast enhanced CT. A feasibility study. Eur Radiol 18:376-383. doi:10.1007/s00330-007-0747-2

59. Bertolotto M (2009) Contrast-enhanced ultrasound: past, present, and future. In: Dogra V (ed) Advances in ultrasound, an issue of ultrasound clinics. Philadelphia: Saunders, pp 339-367

60. Benozzi L, Cappelli G, Granito M, et al. (2009) Contrast-enhanced sonography in early kidney graft dysfunction. Transplant Proc 41:1214-1215. doi:10.1016/j.transproceed.2009.03.029

61. Boggi U, Morelli L, Amorese G, et al. (2009) Contribution of contrast-enhanced ultrasonography to nonoperative management of segmental ischemia of the head of a pancreas graft. Am J Transplant 9:413-418. doi:10.1111/j.1600-6143.2008.02475.x

62. Claudon M, Dietrich CF, Choi BI, et al. (2013) Guidelines and good clinical practice recommendations for contrast enhanced ultrasound (CEUS) in the liver-update 2012: a WFUMB-EFSUMB initiative in cooperation with representatives of AFSUMB, AIUM, ASUM, FLAUS and ICUS. Ultraschall Med 34:11-29. doi:10.1055/s-0032-1325499

63. Sidhu PS, Marshall MM, Ryan SM, Ellis SM (2000) Clinical use of Levovist, an ultrasound contrast agent, in the imaging of liver transplantation: assessment of the pre- and post-transplant patient. Eur Radiol 10:1114-1126. doi:10.1007/s003309900117

64. Sidhu PS, Ellis SM, Karani JB, Ryan SM (2002) Hepatic artery stenosis following liver transplantation: significance of the tardus parvus waveform and the role of microbubble contrast media in the detection of a focal stenosis. Clin Radiol 57:789-799

65. Berry JD, Sidhu PS (2004) Microbubble contrast-enhanced ultrasound in liver transplantation. Eur Radiol 14(Suppl 8):P96-P103

66. Sidhu PS, Shaw AS, Ellis SM, Karani JB, Ryan SM (2004) Microbubble ultrasound contrast in the assessment of hepatic artery patency following liver transplantation: role in reducing frequency of hepatic artery arteriography. Eur Radiol 14:21-30. doi: 10.1007/s00330-003-1981-x

67. Zheng RQ, Mao R, Ren J, et al. (2010) Contrast-enhanced ultrasound for the evaluation of hepatic artery stenosis after liver transplantation: potential role in changing the clinical algorithm. Liver Transpl 16:729-735. doi:10.1002/lt.22054

68. Fernandez CP, Ripolles T, Martinez MJ, et al. (2013) Diagnosis of acute cortical necrosis in renal transplantation by contrast-enhanced ultrasound: a preliminary experience. Ultraschall Med 34:340-344. doi:10.1055/s-0032-1313007

69. Kay DH, Mazonakis M, Geddes C, Baxter G (2009) Ultrasonic microbubble contrast agents and the transplant kidney. Clin Radiol 64:1081-1087. doi:10.1016/j.crad.2009.06.010

70. Missouris CG, Allen CM, Balen FG, et al. (1996) Non-invasive screening for renal artery stenosis with ultrasound contrast enhancement. J Hypertens 14:519-524

71. Blebea J, Zickler R, Volteas N, et al. (2003) Duplex imaging of the renal arteries with contrast enhancement. Vasc Endovascular Surg 37:429-436

72. Ciccone MM, Cortese F, Fiorella A, et al. (2011) The clinical role of contrast-enhanced ultrasound in the evaluation of renal artery stenosis and diagnostic superiority as compared to traditional echocolor-Doppler flow imaging. Int Angiol 30:135-139

73. Blebea J, Volteas N, Neumyer M, et al. (2002) Contrast enhanced duplex ultrasound imaging of the mesenteric arteries. Ann Vasc Surg 16:77-83. doi:10.1007/s10016-001-0144-2

74. Goertz RS, Heide R, Bernatik T, et al. (2012) Mesenteric transit time using contrast-enhanced ultrasound (CEUS) does not corre- 
late with disease activity in Crohn's disease. Ultraschall Med 33:164-169. doi:10.1055/s-0031-1282064

75. Zhou JH, Li AH, Cao LH, et al. (2008) Haemodynamic parameters of the hepatic artery and vein can detect liver metastases: assess- ment using contrast-enhanced ultrasound. Br J Radiol 81:113-119. doi: $10.1259 / \mathrm{bjr} / 25294912$ 